NASA Technical Memorandum 84552

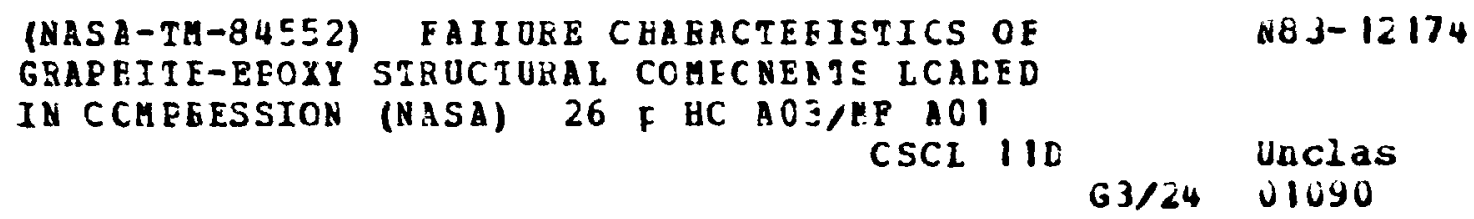

\title{
FAILURE CHARACTERISTICS OF GRAPHITE-EPOXY STRUCTURAI. COMPONENTS LOADED IN COMPRESSION
}

James H. Starnes, JR. and Jerry G. Williams

SePTEMBER 1982

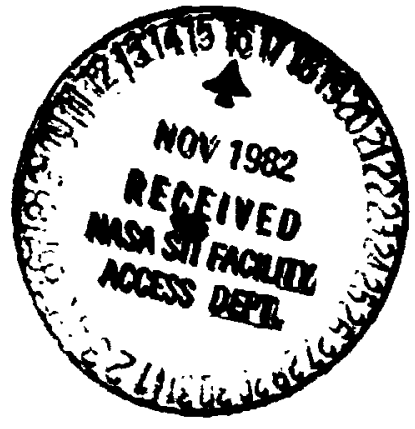

\section{Mns \\ National Aeronautics and Space Administration}




\title{
FAILURE CHARACTERISTICS OF GRAPHITE-EPOXY STRUCTURAL COMPONENTS LOADED IN COMPRESSION
}

\author{
James H. Starnes, Jr. and Jerry G. Williams \\ NASA Langley Research Center \\ Hampton, Virginia 23665
}

\begin{abstract}
SUMMARY
Experimentally observed failure characteristics of compressively-loaded graphiteepoxy components are described in the paper. Experimental results for both strength-critical laminates and structural components with postbuckling strength are discussed. Effects of low-speed impact damage and circular holes on compressive strength are also discussed. Delamination and shear crippling failure mechanisms that limit the performance of strength-critical ?aminates are described. Transverse shear and skin-stiffener separation failure mechanisms that limit the performance of components with postbuckling strength are also described. The influence of matrix properties on compressive-strength improvements for impactdamaged laminates is discussed. Experimental data and results from a failure analysis for strength-critical laminates with cutouts are discussed and compared with test results for impact-damaged specimens. Typical postbuckling test results are compared with analytical predictions.
\end{abstract}

\section{INTRODUCTION}

Current design practices far metal aircraft structures are based on many years of experience and provide ef: - ient, reliable compression-carrying structural components. Some structural components (e.g., wing skins) are designed to be buckling resistant and are usually either strength or stiffncss critical at the design ult imate load condition. Other components (e.g., fuselage skins) are often designed to allow skin buckling to occur at applied loads below those of the design ultimate luad condition. In general, response characteristics and failure mechanisms of these metal components are well established and understood. Design practices for graphite-epoxy aircraft structures are not yet as well established as those for metal structures, but. the experience necessary to understand the behavior of compressively-loaded graphi.e-epoxy structural components is being gained. For exampie, results from tests on stiffened graphite-epoxy panels (e.g., k'illiams and Mikulas, 1975) have shown that buckling-resistant graphite-epoxy stiffened panels can be successfully designed to satisfy the traditional strength and buckling 
requirements used for metal structures and to have significantly lower weights than corresponding structurally-efficient metal panels. Results from tests (e.g., Starnes, Knight and Rouse, 1982) have also shown that stiffened graphiteepoxy panels can have considerable postbuckling strength. However, results from other tests (e.g., Rhodes, Williams and Starnes, 1977, 1978) have shown that compressive strength of graphite-epoxy stiffened panels can be severely reduced by low-speed impact damage typical of that which could occur in service and by local strain concentrations that exist near circular holes. As a result of these compressive-strength reductions, investigations of the failure characteristics and mechanisms of compressively-loaded graphite-epoxy structural components have been conducted.

The present paper summarizes results of research conducted at NASA Langley Research Center to understand the behavior and failure characteristics of laminated graphite-epoxy structural components loaded in compression. Experimental results for both strength-critical laminates and structural components with postbuckling strength are presented, and the effects of low-speed impact damage and circular holes on compressive strength are discussed. Many of the failur mechanisms that limit the structural performance of compressively-loaded components are untque to laminated composites, and some of these mechanisms and their effects on structural performance are described herein. Delamination and shear crippling failure mechanisms that limit the performance of strength-critical laminates are described. Transverse shear and skin-stiffener separation failure mechanisms that limit the performance of structural components with postbuckling strength are also described. The influence of matrix properties on improving the compressive strength of impactdamaged laminates is discussed. A failure analysis that predicts the compressive strength reduction of strength-critical laminates with circular holes is discussed and compared with impact-damage results. Comparisons between typical test results and nonlinear postbuckling analyses are also presented.

\section{SPECIMENS, APPARATUS AND TESTS}

Both unstiffened (Fig. 1) and stiffened (Fig. 2) flat graphite-epoxy specimens were tested. All specimens were fabricated from commercially available 450K-cure preimpregnated graphite-epoxy tape materials. The tape materials were made from Union Carbide Corporation Thornel $300^{1}$ graphite fibers and either Narmco Materials Corporation Rigidite 52081 epoxy resin or American Cyanamide Corporation Cycom $907:$ epoxy resin. Specimens made from Rigidite 5208 epoxy are referred to hereafter as specimens made from $T 300 / 5208$, and those made from Cycom 907 epoxy are referred to as specimens made from T300/BP907. Representative properties used in designing specimens made from these two graphite-epoxy materials are given in Table 1. Some unstiffened $T 300 / 5208$ specimens were stitched through-the-thickness with Du Pont Kevlar $x-100^{1}$ thread in a $6.4-\mathrm{mm}$ by $6.4-\mathrm{mm}$ grid pattern.

A.11 specimens were autoclave cured following the epoxy manufacturer's recommended procedure, inspected ultrasonically, and cut to the desired sizes. The ends of all specimens were ground flat and parailel to permit uniform compressive loading. The ends of the stiffened specimens were also potted in an epoxy resin prior to grinding. Circular holes were machined in the center of some unstiffened specimens with diamond impregnated core drills. One side of each specimen was painted

\footnotetext{
Identification of commercial products and companies in this paper is used to describe adequately the test materials. The identification of these products does not constitute endorsement, expressed or implied, of such products by the National Aeronautics and Space Administration or the publisher of these proceedings.
} 


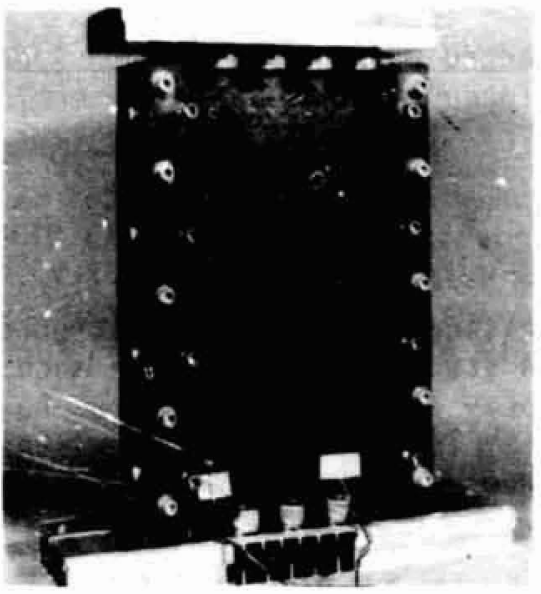

Fig. 1. Specimen mounted in support fixture.

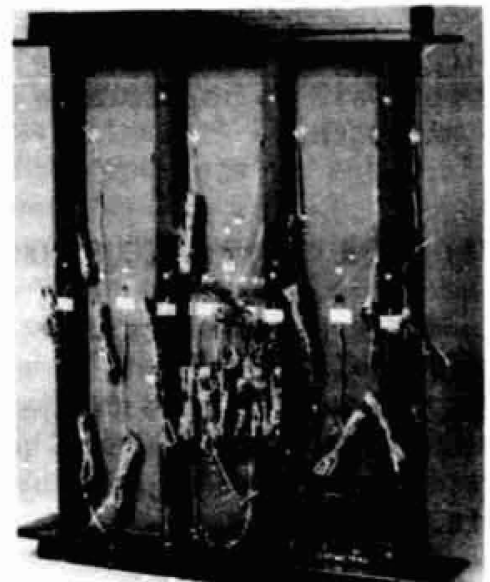

Fig. 2. Stiffened panel specimen.

TMBLE 1 Unidirectional Tape Material Properties Used in Design

\begin{tabular}{lccccc}
\hline Material & $\begin{array}{c}\text { Longitudinal } \\
\text { Modulus, } \\
\text { GPa }\end{array}$ & $\begin{array}{c}\text { Transverse } \\
\text { Modulus, } \\
\text { GPa }\end{array}$ & $\begin{array}{c}\text { Shear } \\
\text { Modulus, } \\
\text { GPa }\end{array}$ & $\begin{array}{c}\text { Major } \\
\text { Poisson's, } \\
\text { Ratio }\end{array}$ & $\begin{array}{c}\text { Ply } \\
\text { Thickness, } \\
\text { Cm }\end{array}$ \\
\hline T300/5208 & 131 & 13 & 6.4 & .38 & .014 \\
T300/8P907 & 111 & 13 & 6.4 & .38 & .016 \\
\hline
\end{tabular}

white to reflect light so that a moire-fringe technique (Dykes, 1970) could be used to monitor out-of-plane deflections.

Hydraulic testing machines were used to load the specimens in axial compression. A machine with a 1.33-MN loading capability was used to test the unst iffened specimens. The ends of these specimens were clamped by fixtures during testing, and the sides were simply supported to prevent wide-column buckling. A typical unstiffened specimen mounted in the support fixtures is shown in Fig. 1 . The length of the unstiffened specimens used to study strength-critical behavior was approximately $25 \mathrm{~cm}$ and the width was approximately $13 \mathrm{~cm}$. The length of the unstiffened specimens used to study postbuckling behavior was approximately $51 \mathrm{~cm}$ and their widths varied from 8 to $24 \mathrm{~cm}$. A machine with a 4.45-MN capacity was used to test the stiffened specimens. The stiffened specimens were flat-end tested without any restraints on the unloaded edges. The lengths of the stiffened panels varied from 51 to $81 \mathrm{~cm}$, the widths varied from 38 to $61 \mathrm{~cm}$, and the stiffener spacings varied from 10.2 to $17.8 \mathrm{~cm}$. Electrical resistance strain gages were used to monitor strains, and direct-current differential transformers were used to monitor longitudinal in-plane and out-of-plane displacements at selected locations. Moire-fringe patterns representing out-of-plane deflections were recorded photographically.

Three types of specimens were tested: specimens without holes or impact damage; specimens with a single circular hole; and specimens that were subjected to lowspeed impact damage. Specimens without holes or impact damage were tested to failure to establish a reference response. Other specimens with either a single circular hole or with low-speed impact damage were also tested to establish the effects of local discontinuities. Impact damage was introduced by propelling $1.27-\mathrm{cm}$-diameter aluminum spheres normai to the plane of the specimen with the compressed air gun described by Rhodes, Williams and Starnes (1977). Some specimens were impacted before any axial load was applied and then tested to determine their residual strength. Other specimens were loaded in compression to a pre- 


\section{Cringing \\ OF POOR QUALITY.}

scribed longitudinal strain level and then impacted while under load. Specimens that did not fail on impact were subsequently loaded to failure to determine their residual strength.

\section{RESULTS AND DISCUSSION}

The failure characteristics of buth strength-critical laminates and structural components with postbuckling strength have been studied. The failure mechanisms that limit the performance of these graphite-epoxy laminated structures has been found to be influenced by local effects caused by low-speed impact, by strain concentrations near holes, and by highly strained and deformed regions of buckled components.

\section{Strength-Critical Laminates With Impact Damage}

Delaminarion and shear crippling failure mechanisms can reduce the compressive strength of strength-critical laminates with impact damage. Results from studies (e.g., Rhodes, Williams and Starnes, 1979; and Starnes, Rhodes and Williams, 1979) have shown that the effects of low-speed impact dalage on the compressive strength of strength-critical structura? components can be determined by testing relatively small 13-cm-wide by 25-cm-long 48-ply laminates. Laminates with these dimensions are representative of the width and stiffness of the skin between stiffeners of panels tested by Rhodes, Williams and Starnes $(1977,1978)$ and have similar reductions in strength due to impact damage.

Effect of impact damage on compressive strength. A typical example of the effect of low-speed impact damage on the compressive strength of a 48-ply T300/5208 orthotropic laminate is shown in Fig. 3. The axial compressive strain applied to the specimen prior to impact is showri on the ordinate and the projectile impact speed is shown on the abscissa. The corresponding projectile kinetic energy is also shown on the abscissa. The filled circles represent specimens that failed on impact and the open circles represent specimens that continued to support the applied load after impact occurred even though they may have sustained local damage. The curve labeled "failure threshold" was faired between the open and filled circles. The data shown on the ordinate represent failures of undamaged specimens and can be used as reference strength values. The data shown in fig. 3 indicate that the laminate compressive strength can be severely reduced by impact damage.

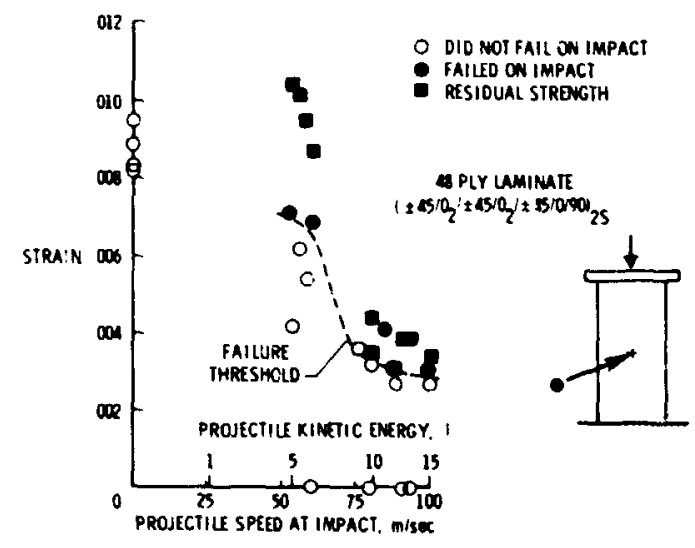

Fig. 3. Effect of low-speed impact on a T300/5208 laminate failure strain. 


\section{ORLGINAL PECE HA \\ OF POOR QUALITY}

Specimens that did not fail during impact, as well as several specimens that were damaged without any applied static load, were subsequently tested to determine their residual compressive strength. The residual strength results are shown by filled square symbols on Fig. 3. Every data point representing residual strength is on or above the failure threshold curve. These results suggest that a failure threshold curve obtained by impacting test specimens while under load is a lower bound for the static compressive strength of graphite-epoxy laminates subjected to low-speed impact damage. The compressive strength: reductions represented by the failure threshold curve in Fig. 3 are typical of the severe strength reductions that can occur for many currently used graphite-epoxy material systems. For example, the failure strain of an undamaged $T 300 / 5208$ orthotropic laminate is reduced from over 0.008 to approximately 0.003 when subjected to impact damage from a projectile with a kinetic energy of $15 \mathrm{~J}$.

Physical characteristics of impact damage. To determine the characteristics of impact damage, specimens were impacted by low-speed projectiles and examined. The specimens were visually inspected for front- and back-surface damage and ultrasonically inspected for indications of interior damage. Some specimens were also cross sectioned through the impacted region and inspected inicroscopically for interior damage. Photographs of the back-surface damage and the ultrasonic C-scan data and a photomicrograph of a cross section through the impacted region of a typical 48-ply orthotropic T300/5208 specimen impacted at approximately $100 \mathrm{~m} / \mathrm{s}$ are shown in Fig. 4. This impact event caused visually detectable back-surface damage and considerab!e interior damage to the laminate as shown in Fig. 4. Interior damage included delaminations between plies with different orientation as well as through-the-thickness matrix cracks. There was no perceptible frontsurface damage at the impact site (indicated by the arrow in Fig. 4).
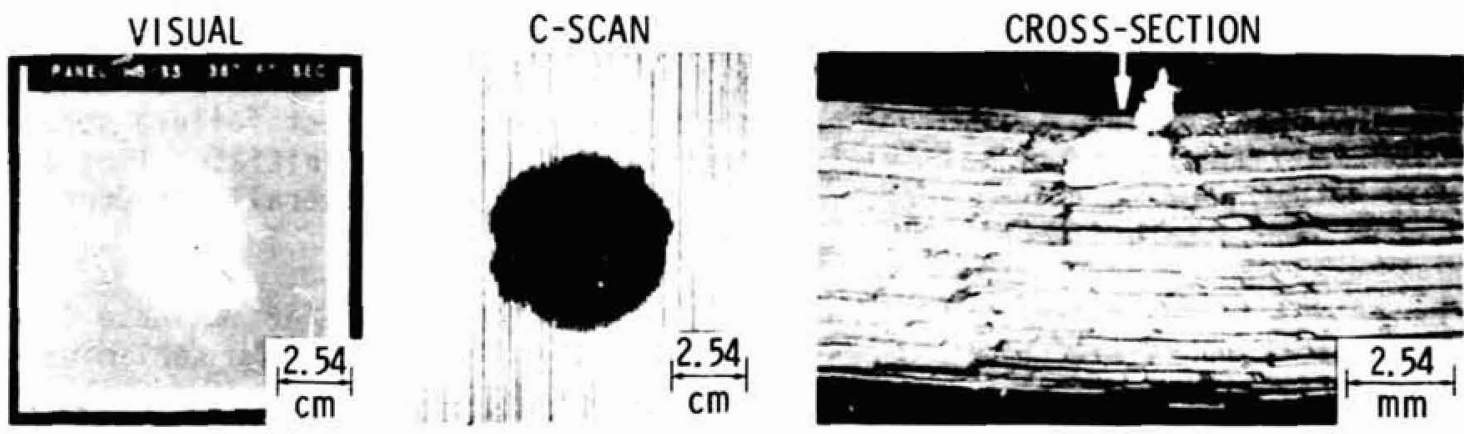

Fig. 4. Damage in a 48-ply $T 300 / 5208$ orthotropic laminate following impact from a $1.27-\mathrm{cm}$-diameter aluminum sphere traveling at $100 \mathrm{~m} / \mathrm{s}$. Arrow indicates impact site.

Several response mechanisms are active in creating the local damage illustrated in Fig. 4. The specimen response sequence following impact is illustrated in Fig. 5 in the temporal order that the events occur. On contact, a transient compressive normal stress wave is initiated and propagates through the laminate. This compressive wave refiects from the back surface as a tension wave and may produce matrix damage. The v-shaped patterns shown in Figs. 4 and 5 are similar to the fracture pattern created by stress waves in homogeneous brittle plates that have been impulsively loaded on one surface. Local transient bending waves are initiated following several reflections of the transient normal waves. The local transient bending deflections of a typical 48-ply laminate impacted at $91 \mathrm{~m} / \mathrm{s}$ were contained within a region with a radius of approximately $2 \mathrm{~cm}$ and had a maximum out-of-plane deflection of approximately $1 \mathrm{~mm}$. Interlaminar stresses associated with the local bending may cause local damage or if damage is present, this local bending deflec- 


\section{ORIGINAL PACE IS OF POOR QUALTTY}

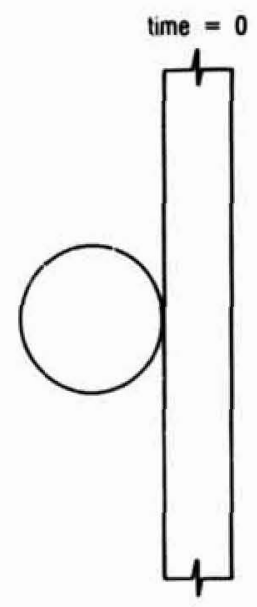

Projectile contact.

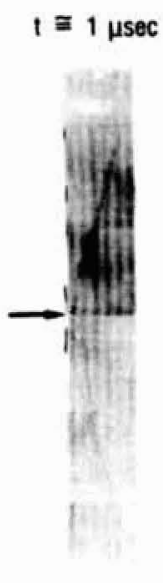

Transient normal wave.

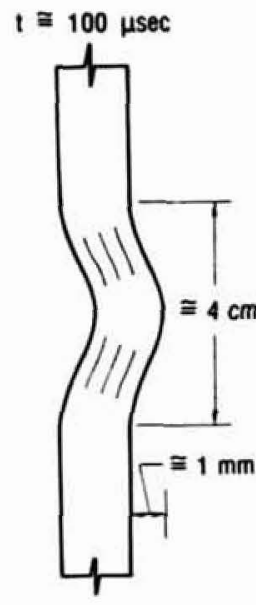

Trancient bendirig wave.

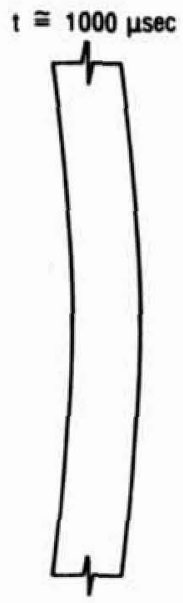

Structural response.

Fig. 5. Response of laminate following low-speed impact.

tion may cause the danage to propagate. To isolate the effect of the local transient bending deflections on failure strength, metal blocks were mounted in close proximity (within $0.1 \mathrm{~mm}$ ) to the back surface of selected specimens to limit the amplitude of the local bending deflections caused by impact. The failure strains for these specimens were significantly higher than the failure strains for similar specimens tested without the metal blocks. This difference in failure strains indicates that the local transient bending deflections can affect failure strength. Deformations due to the overall plate structural response are initiated long after the transient bending wave occurs. It is suspected that the overall structural response caused no additional local damage.

Delamination in an impact-damaged region of a laminate divides the laminate locally into a number f sublaminates. The local bending stiffnesses of the sublaminates are significantly lower than those of the original laminate and, as a result, a sublaminate may buckle at an applied strain that is significantly lower than the strain required to buckle or to fail the undamaged laminate. An example of local sublaminate buckling and subsequent delamination propagation that was observed during the residual-strength test of an impact-damaged laminate is shown by the moire-fringe pattern photographs in Fig. 6. The first photograph shows the local surface damage caused by impact and the succeeding photographs show the buckled sublaminate and the damage propagation across the specimen with increasing applied load. The amplitude of the sublaminate buckling mode grows with increasing applied load, and it is suspected that high values of stress are developed in the matrix at the delamination boundary. When the matrix stresses at the delamination boundary exceed the critical stress of the matrix, the buckled delamination grows in size until the matrix stresses at the delamination boundary are relieved. Additional loading eventually causes the buckled delamination to propagate completely across the laminate as shown in the right photograph. Analyses of this propagating delamination phenomenon have been developed by Chai, Babcock, and Knauss (1981) for beams and by Chai (1982) for plates. These analyses couple the effect of local buckling with a fracture mechanics-based energy release rate criterion. These analytical results are qualitatively consistent with the experimental observations shown in Fig. 6 . 

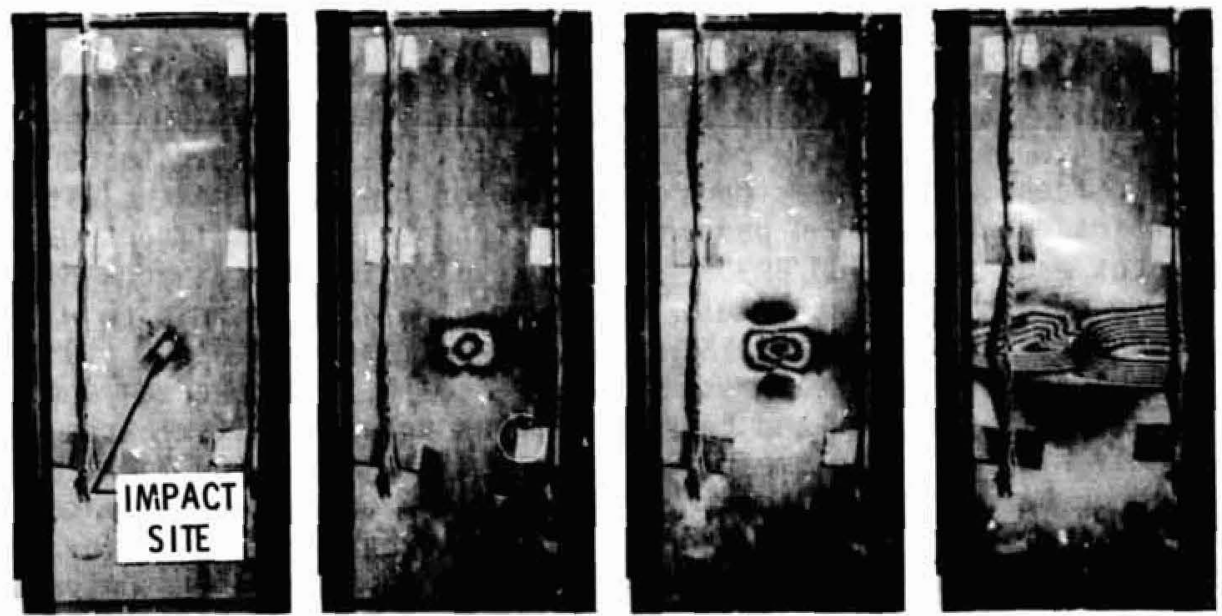

Fig. 6. Propagation of impact damage with increasing compressive load.

Impact damage tolerant materials. The identification of delamination as a cause of compressive strength reduction of impact-damaged T300/5208 laminates suggested that the use of a delamination-resistant resin material might improve a laminate's tolerance to impact damage. Although the specific material requirements that could improve delamination resistance are not well understood, it was anticipated that a delamination resistant resin material should have a greater strain at failure than the 1.5 percent characteristic of T300/5208.

A study of the effect of resin formulation on the impact damage tolerance of graphite-epoxy laminates was conducied by Williams and Rhodes (1981). Laminates with the same graphite fiber and stacking sequence were made from each of 24 different resins. The neat resin failure strain for most of the resins was greater than 4 percent. The laminates were subjected to impact damage with no ap-lied load and then tested to determine their residual strength. Five of the resins were significantly more impact damage tolerant than the others. Ultrasonic inspection showed that laminates made from these five damage tolerant resins had smaller areas of local damage than the other laminates for identical impact conditions, and the residual strength tests showed that the damage tolerant laminates failed at higher strains. The failure threshold curve for one of the damage tolerant material systems, namely T300/BP907, is compared in Fig. 7 with the failure threshold curve for $T 300 / 5208$. For the range of test conditions considered, the impact damaged T300/BP907 laminate failed at significantly higher strains than the impact-damaged $T 300 / 5208$ laminate. These results indicate that the properties

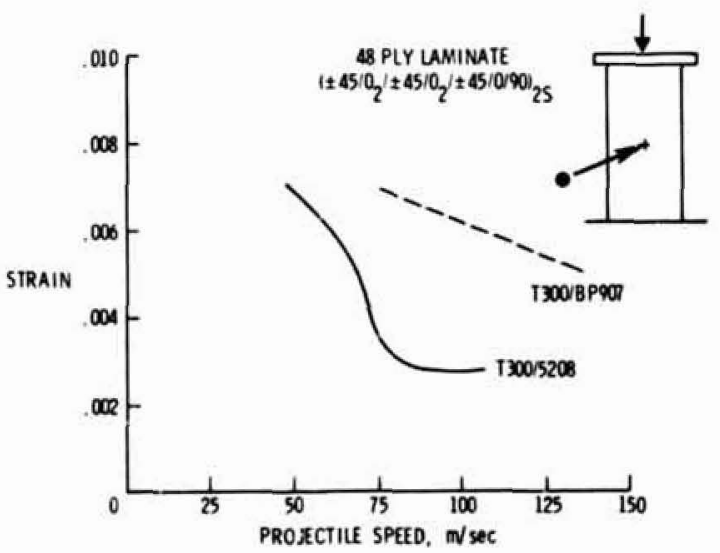

Fig. 7. Failure threshold curves for impact-damaged graphite-epoxy laminates made from different resins. 


\section{ORIGINAL PAC:E IS \\ OF POOR QUALITY}

of the matrix material have a considerable effect on the impact damage tolerance of graphite-epoxy laminates. The strain at failure for Cycom 907 neat resin is approximately 4.8 percent while the strain at failure for Rigidite 5208 neat resin is only 1.5 percent. Laminates made from some of the other resins with neat resin failure strains greater than 4 percent were found to be less impact damage tolerant than laminates made from $T 300 / B P 907$. These results indicate that a high neat. resin failure strain will not necessarily guarantee that a laminate will be impact damage tolerant. The results of the study by Williams and Rhodes (1981) indicate that in addition to a high neat resin failure strain, an impact damage toleran: resin should have high shear and tension modulus values and laminates should have a sufficiently high resin volume fraction (e.g., 40\%) to allow local plastic deformation to occur between the fibers. Although improved damage tolerance is an important consideration, other factors such as strength retention for elevatedtemperature and moisture-content conditions are also important. Unfortunately, many of the changes in resin formulations that have been considered for improving damage tolerance adversely affect other desirable properties and, as a resulf. compromises are likely to be necessary when developing improved resin formulations.

Another approach for suppressing delamination in graphite-epoxy laminates is to provide transverse reinforcement to the laminate. One such reinforcing concept (e.g., Rhodes and Williams, 1981) is to stitch the laminate prior to curing with high-strergth threads. A comparison of impact damage failure threshold data for T300/5208 and T300/BP907 laminates with and without transverse stitching is presented in Fig. 8. Transverse stitching significantly increased the failure threshold strains for the delamination prone $T 300 / 5208$ laminates but had no effect on the failure threshold strains for the delamination resistant T300/BP907 laminates.

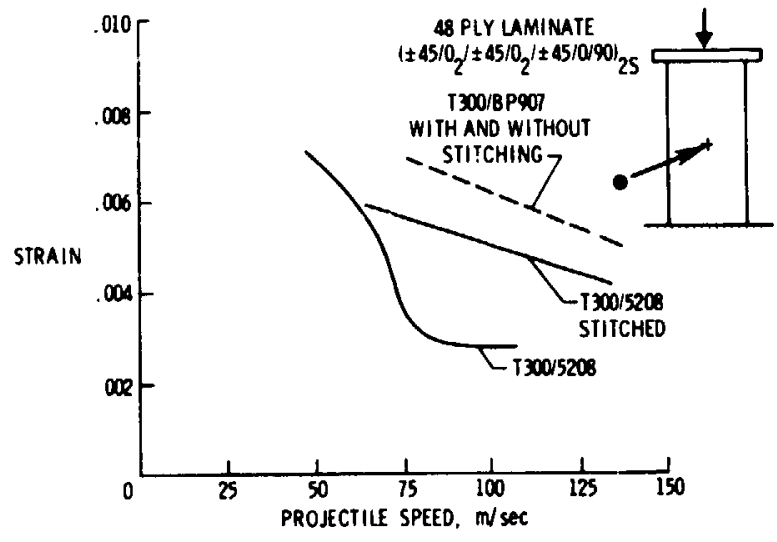

Fig. 8. Effect of transverse stitching on failure threshold curves of impactdamaged graphite-epoxy laminates.

Failure characteristics of impact damage tolerant laminates. Cross sections of failed T300/5208 and T300/BP907 impact damaged laminates are shown in Fig. 9. The cross section of the $T 300 / 5208$ laminate indicates that extensive delamination has occurred. The cross section of the T300/BP907 laminate indicates that the laminate has failed in a transverse shear crippling mode rather than by delamination. The T300/5208 laminates with transverse stitching also falled in this transverse shear crippling mode. Apparentiy, suppressing delamination, either by the use of a delamination resistant resin or by transverse stitching, can raise the laminate failure strain to a level where the shear crippling failure mechanism becomes critical. 


\section{ORIGINAL PAGE IS \\ OF POOR QUALITY}
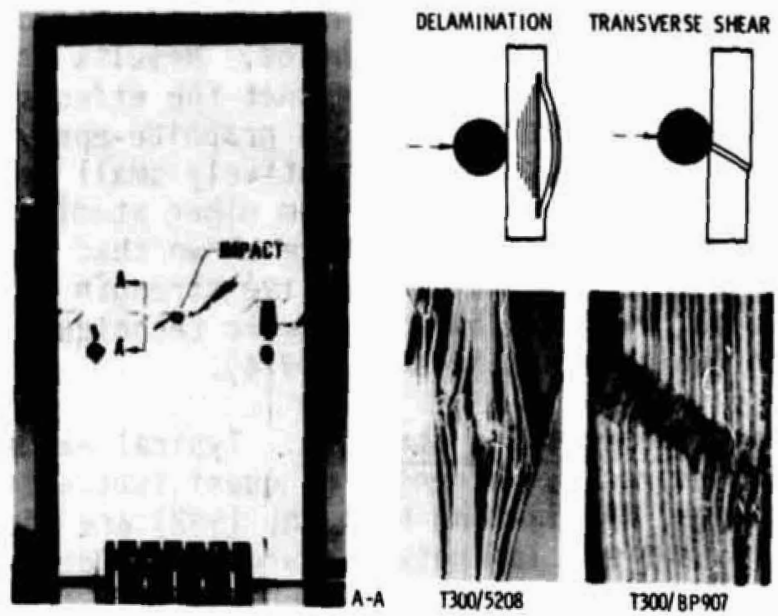

Fig. 9. Impact-damage initiated failure modes.

A high magnification photograph of a cross section through the failed region of an imfact-damaged T300/BP907 laminate is shown in Fig. 10. The band of broken fibers shown in Fig. 10 runs across two $0^{0} \mathrm{plies}$ and appears to be a fiber shear crippling failure mode. The broken pieces of the fibers are approximately four fiber diameters long. Impact damage may cause local strain concentrations, local changes in fiber curvature and local fiber-to-matrix bond failures in addition to delamination. Apparently, these local effects coup?e with the applied compressive load to cause fiber microbuckling which, in turn, can cause sufficiently high local bending and extensional strains to fail the fibers by shear crippling. The broken fibers in this specimen were only observed to occur in $0^{\circ} \mathrm{plies}$ which are coilinear with the applied compressive loading direction. Apparently, the local buckling of the 00 fibers initiates the transverse shear crippling failure of the laminate shown in Fig. 9 .

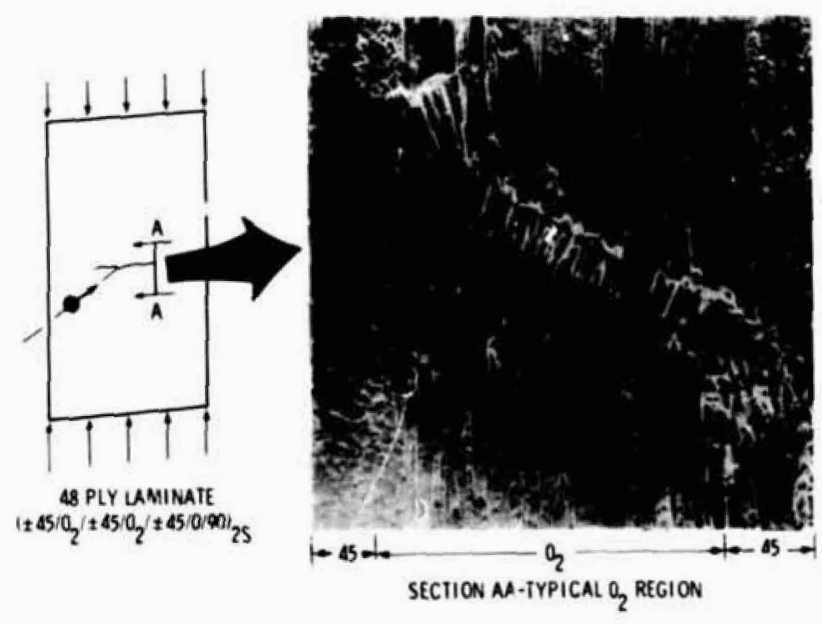

Fig. 10. Scanning electron photomicrograph of cross section showing shear crippling failure mode. 
Strength-Critical Laminates with Circular Holes

\author{
ORIGITAL PACPL IS \\ OF POOR QUALITY
}

The strain concentrations near holes cause reductions in the compressive strength of strength-critical laminates with circular holes. Results from studies (e.9., Starnes, Rhodes and Willians, 1979) have shown that the effects of circular holes on the compressive strength of strength-critical graphite-epoxy structural components can be determined by testing the same relatively small laminater 1 . to study the effects of impact damage. Results from other studies $(e, a$, in: $k$. ., 1980; and Rhodes, Mikulas and McGowan, 1982) have shown that the ef , its o1 $111-$ nate width and stacking sequence on the compressive strength of graphite-epoxj; laminates with holes can be predicted by a heuristic techniques known as the point stress failure criterion (Whitney and Nuismer, 1974).

Effect of circular holes on compressive strength. Typical examples of the effects of circular holes on the compressive strength of quasi-isotropic T300/5208 and T300/BP907 laminates (Rhodes, Mikulas and McGowan, 1982) are shown in Fig. 11. The test results indicate that the laminate failure strain decreases as the hole diameter increases and that there is little difference in the effects of circular holes on the compressive strengths of the laminates made from the two resins. Mikulas (1980) showed that the results could be bounded by simple notch-insensitive and notch-sensitive failure criteria. The notch-insensitive curve represents results for materials that allow yielding or other forms of relief from the strain concentrations at the hole edge to occur. For notch-insensitve material, the failure strains are di.ectly proportional to the reduction in the specimen cross section. The notch sensitive curve represents results for materials that fail when the strain concentration at the hole edge equals the fallure strain of the material. The results in Fig. 11 indicate that the notch-sensitive failure prediction underestimates laminate failure by a noticeable amount when the a/w ratio is less than 0.2 for these $13-\mathrm{cm}-$ wide specimens. This difference in failure results indicates that one or more local mechanisms (e.g., delamination, shear crippling, or softening due to material or geometric nonlinearities) act to relieve the high strain concentrations at the edge of the hole. These local relief mechanisms can be accounted for successfully when predicting the failure of compressively-loaded laminates with holes by using a heuristic point stress failure prediction criterion (Whitney and Nuismer, 1974). The point stress failure criterion assumes that failure occurs when the stress (strain) at a characteristic value from the edge of a hole reaches the ultimate stress (strain) of the material. Failure predictions based on the point stress failure criterion aoree with the tes: results shown in Fig. 11.

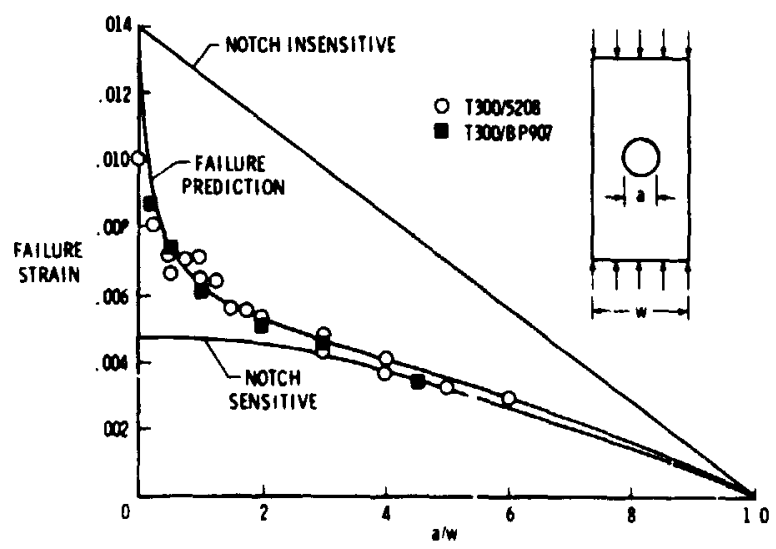

Fig. 11. Effect of varying hole diameter on the failure strain of 48-ply quasi-is itropic specimens made from two different graphite-epoxy materiai.. $w=13 \mathrm{~cm}$. 


\section{ORLGINAL PAGE IS OF POOR QUALITY}

The effects of transverse stitching on the fallure strains of T300/5208 laminates with holes are shown as a function of $a / w$ ratio in Fig. 12. Results of unstitched T300/5208 laminates with holes are also shown in Fig. 12 for comparison. The results indicate that transverse stitching has no apparent effect on the failure strains of laminates with holes and that the point stress failure criterion predicts the failure strains reasonably well. The failure mechanism for laminate with circular holes is discussed in the next section.

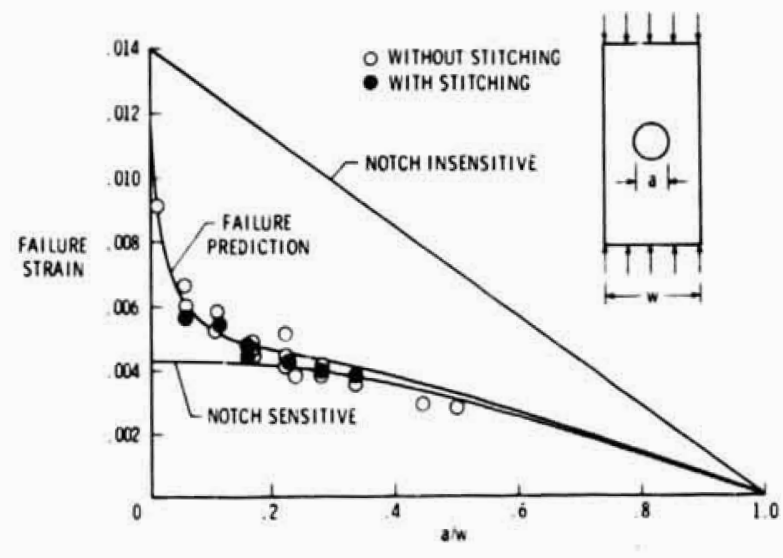

Fig. 12. Effect of varying hole diameter on the failure strain of 48-ply orthotropic $T 300 / 5208$ specimens with and without transverse stitching. $w=11.4 \mathrm{~cm}$.

Failure characteristics of larinates with holes. I ieries of photographs of moirefringe patterns that highights the propagation of camage in the vicinity of : 1.91-Cm-diameter hole in a T300/5208 laminate is shown in Fig. 13. The moi fringe patterns represent local out-of-plane deformations that appear $t)$ bi i ed delaminations. A cross section through the hole of the fafled laminate is shu w in the far right photograph in Fig. 13, and many delaminations and broken fibers are evident. For applied loads below 93 percent of the ultimate failure load of the laminate, there were no local failures indicated by the moire-fringe patterns.
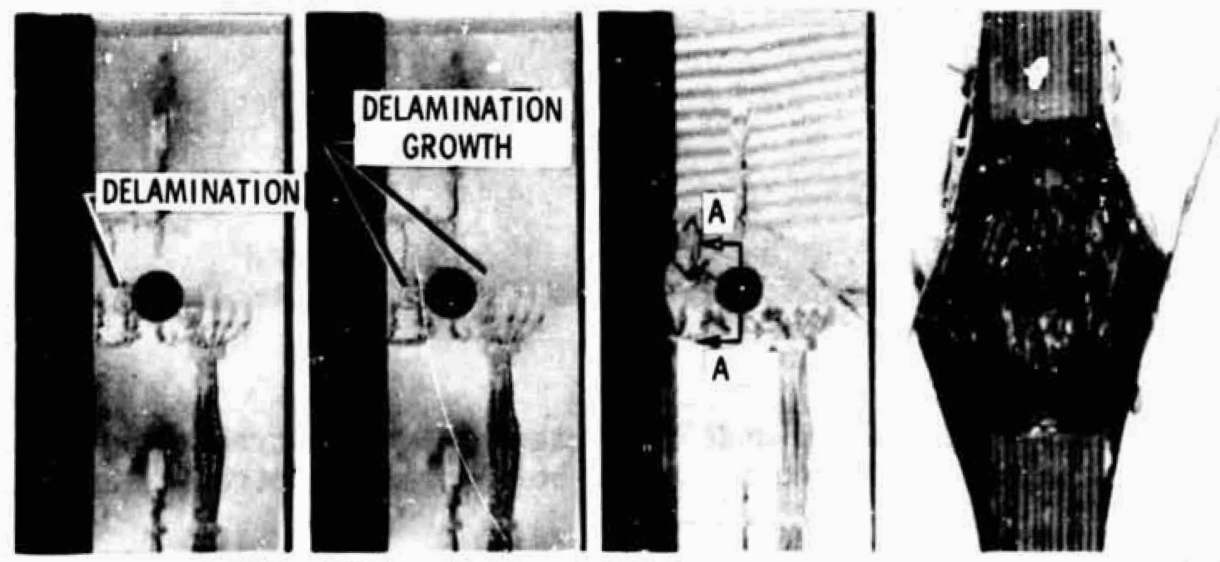

$P / P_{u l t}=0.94$. $P / P_{u l t}=0.98$. Failed specimen. Cross section $A-A$.

Fig. 13. Propagation of local failures in a graphite-epoxy specimen with a 1.91$\mathrm{cm}$-diameter hole. Moire-fringe patterns indicate apparent delamination. 
The similarities between the compressive strength reductions for unstitched $T 300 /$ 5208 laminates (delinination prone when impacted) and stitched T300/52.08 and T300/ BP907 laminates (b th delamination resistant when impacted) with holes (see Figs. 11 and 12) suggest $h$ a local failure mechanism other than delamination may occur at applied loaas below those corresponding to the visible local failures shown in Fig. 13. To determine if such a mechanism exists, a laminate specimen with a hole was loaded to less than the expected failure load; and then unloaded without any visible evidence of local failures. A small section was cut from the region adjacent to the hole where a high stri in concentration exists. The outer fourteen plies were ground away to expose an interior $0^{\circ} \mathrm{ply}$, and a scanning electron photomicrograph of this $0^{\circ}$ ply is shown in Fig. 14. The pattern of broken fibers on the micruscopic level suggests a shear crippling failure mode exists that may have been initiated by microbuckling of the graphite fibers. Apparently, the strain concentrat; at the edge of the hole is sufficiently large to cause local microbuckling of the $0^{\circ}$ fibers, and the conbination of bending and axial strains causes these fibers to fail in the shear crippling mode at applied loads below those corresponding to the visible local failures shown in Fig. 13. The loads that were supported by the broken fibers are subsequently redistributed to adjacent fibers away from the hole. For small holes (a/w $<0.2$ for these specimens) the strain concentration near the hole decays to the average laminate strain within a small distance from the hole edge. As a result, the loads formerly supported by the broken fibers are redistributed to other fibers that are below the critical microbuckling strain and no additional fibers are broken until a higher load is applied. This load redistribution into a region of lower st.rains may provide some of the strain relief necessary to allow laminates to support loads greater than those corresponding to the notch-sensitive failure curve shown in Fig. 11. For large holes $(a / w>0.2)$ a larger region near the hole is t: ghily strained and the loads from the broken fibers are redistributed to a highly strained region where additional fiber failures can occur without any additional applied load. This load redistribution into a highly strained region may explain why the failures of lani., ates with larger holes are likely to correspond to the failures predicted by the notch sensitive results in Fig. 11.
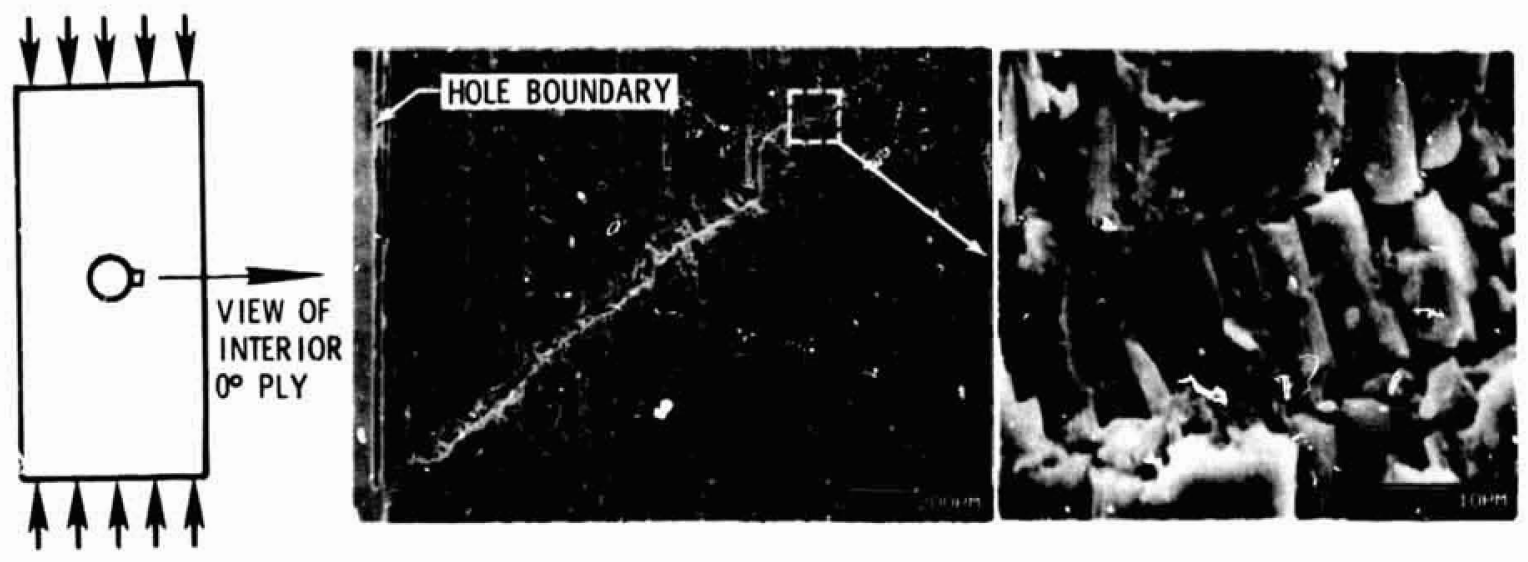

Fig. 14. Shear crippling failure mode initiated by fiber microbuckling in a hign strain concentration region near a hole in an orthotropic laminate.

Comparison of effects of impact oamage and holes. Both impact damage and circular holes have been shown to reduce the compressive strength of graphite-epoxy laminates. A comparison of the effects of impact damage and holes on failure strain is shown in Fig. 15 for a ${ }^{\top 200 / 5208}$ laminate. The open circles represent hole data for both stitched at, unstitched laminates from Fig. 12. The dashed curve 


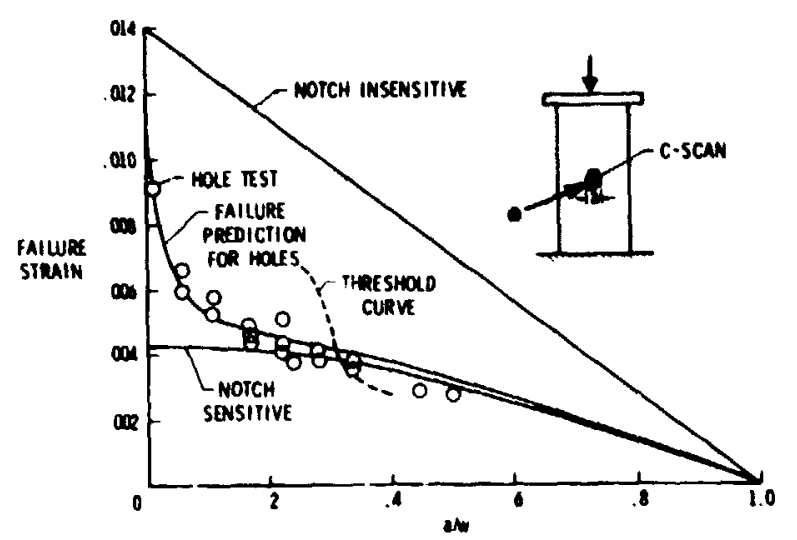

ORLGINAL. P:S

OF POOR QUALITY

Fig. 15. Comparison of failure strains of 48-ply T300/5208 orthotropic laminates with holes and impact damage. $w=11.4 \mathrm{~cm}$.

represents impact data for unstitched $T 300 / 5208$ laminates. To generate the dashed or impact curve, the failure strains from Fig. 3 were plotted as a function of an ultrasonically-determined damage width (Rhodes, Williams and Starnes, 1979) for the corresponding impact speed. By plotting the impact data in this manner, hoies appear to reduce the compressive strength of these $T 300 / 5208$ laminates more than impact damage when the $a / w$ ratio is less than 0.3 and slightly less than impact damage when the $a / w$ ratio is greater than 0.3 .

\section{Unstiffened Laminate; with Postbuckling Strength}

Failures in highly deformed and strained regions limit the posthuckling strength of unstiffened laminates. The effects of circular holes and low-speed impact damage may also 1 imit the postbuckling strength of a laminate. Typical graphite-epoxy unstiffened 16- and 24-ply quasi-isotropic specimens and 24-ply orthotropic specimens were tested by Starnes ard Rouse (1981). The specimens were $51 \mathrm{~cm}$ long and had length-to-width ratios ranging from 2.1 to 6.7 and width-to-thickness ratios ranging from 24 to 115 .

Postbuckling behavior of unstiffened laminates. Typical end-shortening results (Starnes and Rouse, 1981) are shown as a function of the applied compressive load in Fig. 16. The reduction in longitudinal stiffness that occurs after buckiing is illustrated by the change in slope of these load-shortening curves. In Fig. 16,

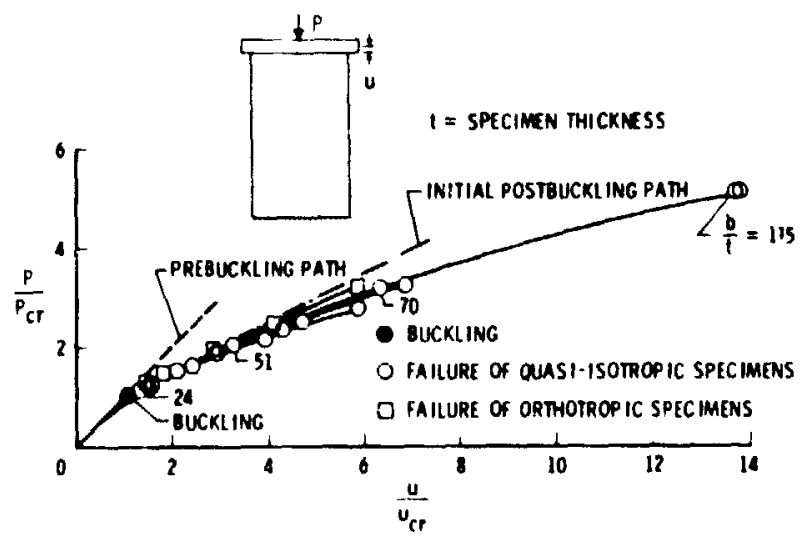

Fig. 16. Postbuckling response of 16- and 24-ply unstiffened graphite-epoxy laminates. $t=$ specimen thickness. 


\section{ORLGINAL PAGE IS
OF POOR QUALITY}

the applied load $P$ and end-shortening displacement $u$ are normalized by the analytical buckling load $\mathrm{P}_{\mathrm{Cr}}$ and corresponding end shortening at buckling $\mathrm{u}_{\mathrm{Cr}}$ determined by the STAGS analysis code (Almroth and Brogan, 1978). Buckling is indicated by the filled circle in Fig. 16, and failure of the specimens is indicated by the open symbols. The open circles represent failure of the quasiisotropic specimens and the open squares represent failure of the orthotropic specimens. The width-to-thickness ratios b/t for several typical specimens are shown on Fig. 16, and the results indicate that the ratio of failure load to buckling load for these specimens increases with $\mathrm{b} / \mathrm{t}$ ratio.

The effects of varying the specimen aspect ratio $L / b$ and width-to-thickness ratio b/t on the postbuckling response of typical 51-cm-long, 24-r?y orthotropic specimens (Starnes and Rouse, 1981) are shown in Fig. 17. The end shortening u of each specimen normalized by the specimen length $L$ provides a measure of the specimen longitudinal strain and is shown as a function of the applied load $P$ normalized by the specimen membrane stiffness EA. The circles on the figure represent initial buckling and the plus signs represent specimen failure. The data indicate that the strain at buckling increases and the ratio of the strain at failure to the strain at buckling decreases as $\mathrm{L} / \mathrm{b}$ increases and as $b / t$ decreases.

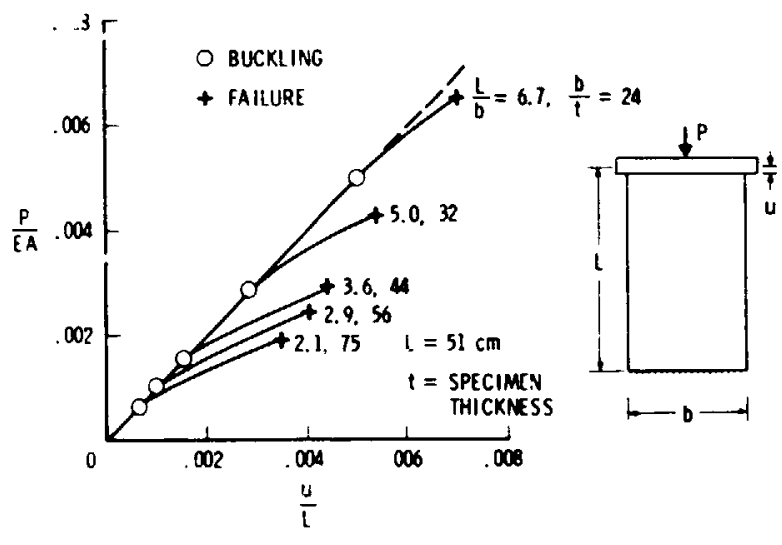

Fig. 17. Postbuckling response of unstiffened graphite-epoxy laminates with different aspect 1 atios. $t=$ specimen thickness.

Longitudinal surface strain measurements just before failure from nine pairs of back-to-back strain gages distributed across a typical 16-ply specimen at two locations are shown in Fig. 18. The gage location $y$ is nermalized by the specimen width b. One ruw of strain gage pairs was located so the center pair would be near a point of maximum out-of-plane deflection, and the data for this row are shown in Fig. 18a. The other row of gages was located near a buckling-mode nodal line, and the data for this row are shown in Fig. 18b. The measured data are represented by the circles on the figure. The curves on the figure are the average of the strains for each pair of gages and represent the membrane strain. No gages were located at the specimen edges so an estimate if the membrane strains near the edges based on measured end shortening data is represented by the dashed parts of the curves. As expected, the data indicate that the bending strain is greatest in the specimen center near the point of maximum out-of-plane deflection and that the membrane strain is greatest near the specimen edges. A photograph of the moirefringe pattern representing the out-of-plane deflections of a typical 16-ply specimen just before failure is shown in Fig. 19a. Failure occurred across the specimen at a nodal line as indicated by the moire-fringe pattern shown in fig. 19b. The failure mode appears to be a shear faflure mode as shown in Fig. 19c. Apparently, the higher membrane strains near the specimen edges couple with the 


\section{ORIGINAL PAGE IS \\ OF POOR QUALITY}

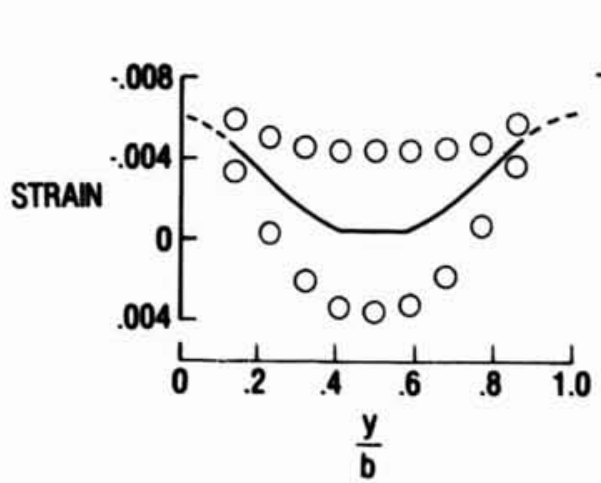

(a) Strains near a point of maximum out-of-plane deflection.
O SURFACE STRAIN MEMBRANE STRAN

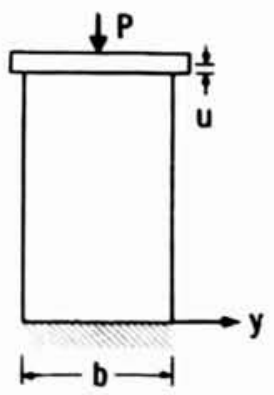

(b) Strains near a bucklingmode nodal line.

Fig. 18. Longitudinal strain distributions across a laminate loaded to 3.26 times its buckling load.

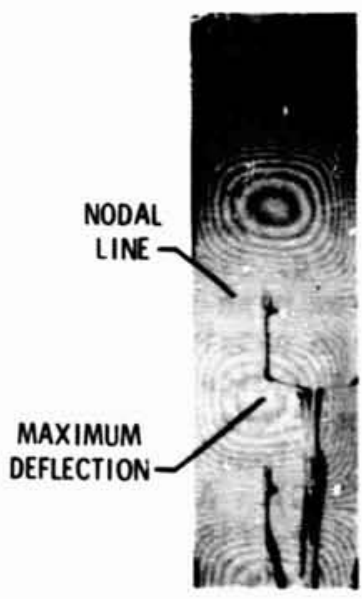

(a) $P / P_{\text {Cr }}=3.06$.

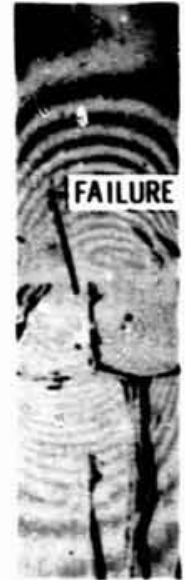

(b) Failed specimen.

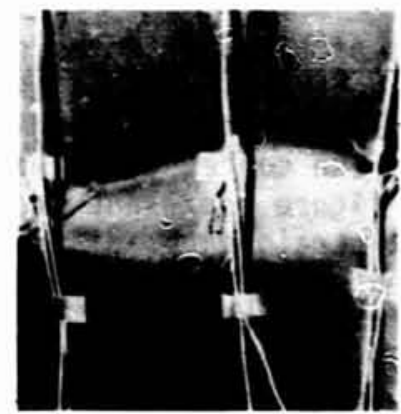

(c) Shear failure mode.

Fig. 19. Out-of-plane deflection patterns and failure mode of an unstiffened graphite-epoxy laminate with postbuckling strength.

out-of-plane deflection gradient at the nodal line to induce sufficient transverse shearing forces to fail the specimen in shear before the large bending strains at the points of maximum out-of-plane deflection become critical. All of the specimens represented by the data in Fig. 16 failed across the specimen at a nodal line.

A comparison between test results and analytical results obtained with the STAGS analysis code (Almroth and Brogan, 1978) is shown in Fig. 20 for a typical 24-ply orthotropic specimen. End shortening u normalized by the end shortening at buckling $u_{\mathrm{cr}}$ (Fig. 20a), out-of-plane deflection $w$ at a point of maximum deflection normalized by the specimen thickness $t$ (Fig. 20b), and the longitudinal surface strain at a point of maximum out-of-plane deflection (Fig. 20C) are shown as functions of the applied load $P$ normalized by the buckling load $P_{c r}$. An initial geometric imperfection with the same shape as the buckling mode 


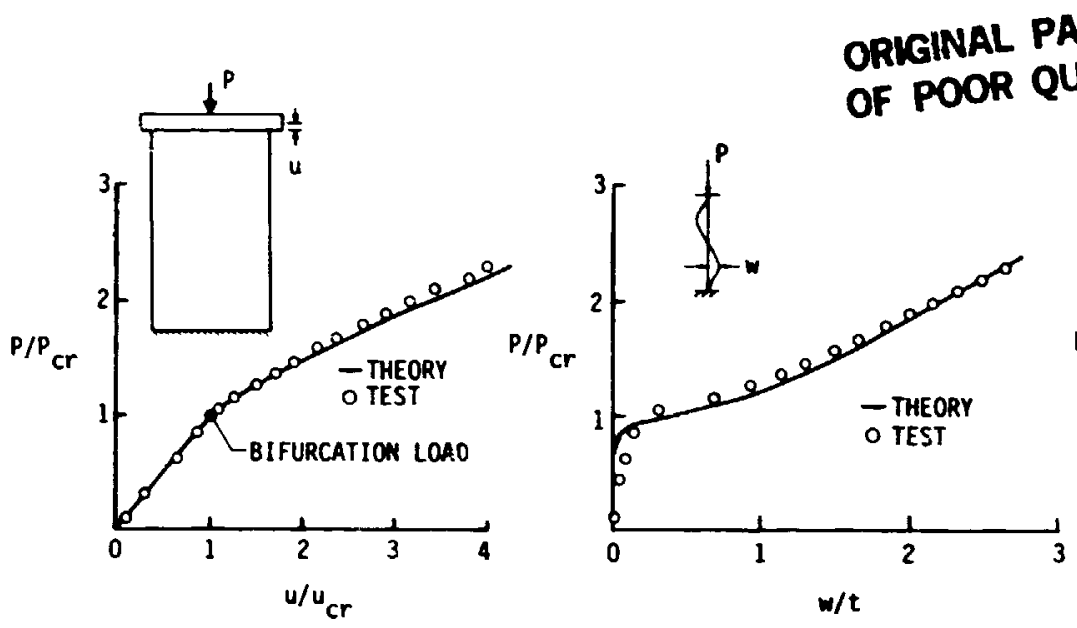

(a) End shortening. (b) Out-of-plane deflection.

\section{AGE IS \\ QUALIT}

Fig. 20. Comparison of experimental and analytical postbuckling results. $t=$ specimen thickness.

was used in the nonlinear analysis. The amplitude of the initial imperfection was assumed to be small. The experimental and analytical results shown in the figure correlate well up to failure. A capability for reliably and accurately predicting failure is not yet available.

Effects of circular holes on postbuckling behavior. The effects of circular holes on the postbuckling response of unstiffened laminates were studied by Starnes and Rouse (1981), and the longitudinal strain distribution near a 1.91-cm-diameter hole in the center of a typical 24-ply specimen is shown in Fig. 21 The circles in the figure rejresent measured longitudinal strain data from nine pairs of backto-back strain gages distributed across the specimen on a line passing through the hole center. Prior to buckling, the specimen remains flat as indicated by the moire-fringe pattern of Fig. 22a. The strain distribution near the hole shown in Fig. 2la for the specimen loaded to 90 percent of its buckling load is similar to results found in many classical references (e.g., Howland, 1930). After buckling, the specimen is deformed out of plane as indicated by the moire-fringe pattern shown in Fig. 22̌b. The moire-fringe pattern indicates that the hole is near a
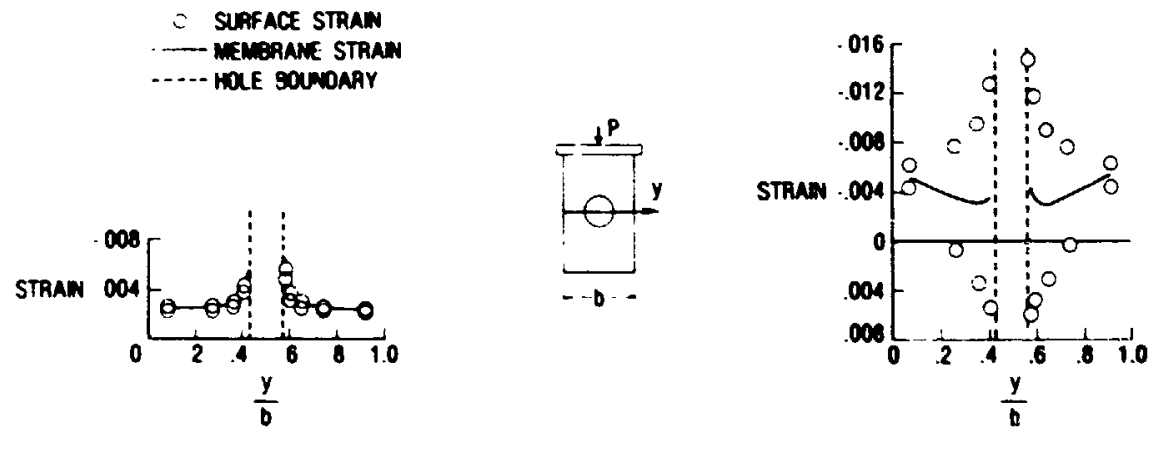

(a) $P / P_{C r}=0.90$.

(b) $\mathrm{P} / \mathrm{P}_{\mathrm{Cr}}=1.39$

Fig. 21. Longitudinal strain gage data near a circular hole. 

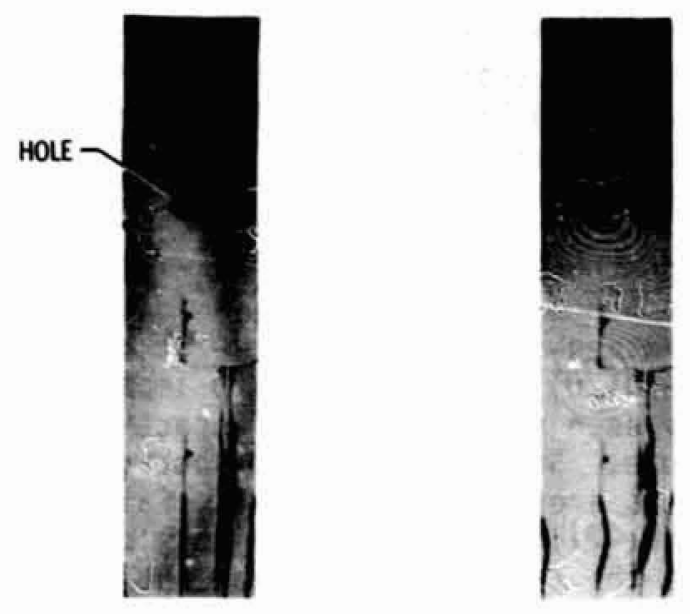
(a) $P / P_{C r}=0.90$.
(b) $\mathrm{P} / \mathrm{P}_{\mathrm{Cr}}=1.39$.

Fig. 22. Out-of-plane deflection patterns for an unstiffened laminate with a circular hole.

point of maximum out-of-plane deflection of the buckling mode and the strain distribution near the hole shown in Fig. 2lb indicates that buckling causes a change in strains across the panel to include large local bending strain components at the edge of the hole and large membrane strains at the specimen edges.

The results showing the effects of holes on the postbuckling behavior of some typical laminates are shown in Fig. 23 and are compared with similar results for specimens without holes. The filled circles in Fig. 23 represent failure of specimens without holes, and the open circles represent failure of specimens with holes. The results for two typical 16-ply laminates with $L / b=2.2$ and $b / t=109$ are shown in the figure. One specimen had a 1.91-cm-diameter hole, and the other had no hole. The response curves are virtually the same for the two specimens, and fail$v$ occurred along a buckling-mode nodal line in both cases with no apparent influence of the hole. The results for three typical 24-ply specimens with $L / b=5.0$ and $b / t=30$ are also shown in the figure. One specimen had a $0.95-\mathrm{cm}-$ diameter hole, one had a 1.91-cm-diameter hole, and the third specimen had no hole. All three specimens had similar response characteristics up to failure. The specimens with holes failed at lower loads than the specimen without a hole, and failure occurred along a line across the laminate through the hole rather than

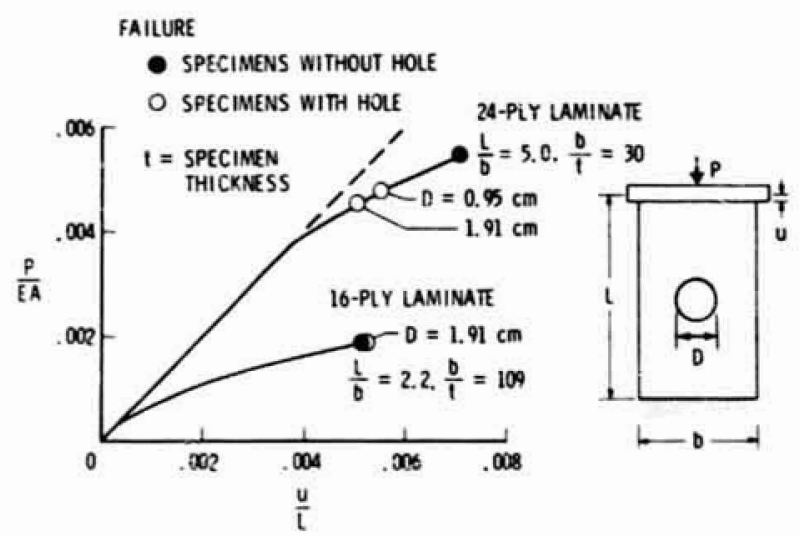

Fig. 23. Effect of circular holes on the postbuckling response of unstiffened laminates, $\mathrm{t}=$ specimen thickness. 


\section{ORIGINAL PAGE IS
OF POOR QUALITY}

aleng a buckling-mode nodal line. Apparently the local strains near the hole (e.g., Fig. 21b) were sufficient to cause failure to occur at the hole. These limited results suggest that the postbuckling strength of laminates that have relatively high initial buckling strain will be influenced more by a hole than laminates with relatively low initial buckling stains.

Effects of impact damage on postbuckling behavior. The effects of low-speed impact damage on the postbuckling response of unstiffened laminates were studied by Starnes and Rouse (1981). Sixteen- and 24-ply quasi-isotropic specimens (L/b of 3.6 and $5.0 ; \mathrm{b} / \mathrm{t}$ between 30 and 70 ) were subjected to impact damage that ranged from barely visible to easily seen surface damage (impact speeds between 43 to 95 $\mathrm{m} / \mathrm{s}$ ) and then tested to failure. Some typical load-shortening results for impactdamaged and undamaged specimens are shown in Fig. 24. Failure of the undamaged specimens is represented by the filled circles. Failure of specimens impacted at the midpoint of a line across the specimen width near the location of maximum out-of-plane deflection is represented by the open circles. Failure of 16-ply specimens impacted within $3.2-\mathrm{cm}$ of a specimen edge (where the postbuckling membrane strains are righest) is represented by the open squares. All 24-ply specimens failed across the specimen through the impact site at applied loads less than the failure load of the corresponding undamaged specimen. The 16-ply specimens impacted at the midpoint of a line across the specimen failed across the specimen along a buckling-mode nodal line some distance from the impact site as indicated by the moire-fringe patterns shown in Fig. 25. The 16-ply specimens impacted near the specimen center failed at approximately the same failure load as the corresponding undamaged specimens. The 16-ply specimens impacted near the specimen side failed across the specimen through the damage site at a load below the failure load of the corresponding undamaged specimens.

These limited test results indicate that specimens with low-speed impact damage may have reduced postbuckling strength. The results shown in Fig. 24 suggest that the failure loads of specimens with relatively high initial buckling strains can be reduced more than the failure loads of specimens with lower initial buckling strains. The results also indicate that the impact-damage location can affect postbuckling strength. A specimen impacted in regions where the postbuckling membrane strains are relatively low will have a higher failure load than a similar specimen impacted where the postbuckling membrane strains are high.

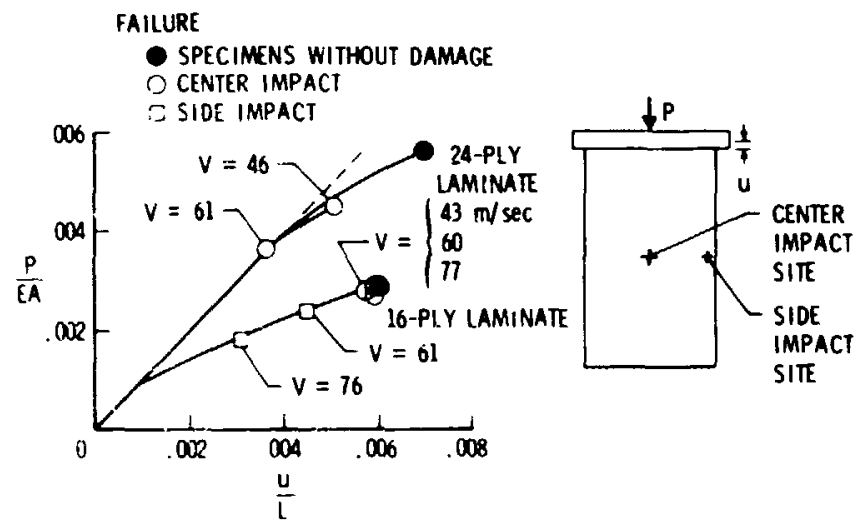

Fig. 24. Effect of low-speed impact damage on the postbuckling response of unstiffened quasi-isotropic laminates. 


\section{ORIGINAL PAGE IS \\ OF POOR QUALITY}

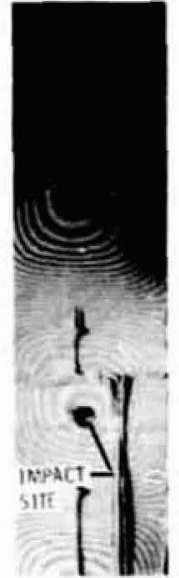

(a) $\mathrm{P} / \mathrm{P}_{\mathrm{cr}}=3.15$.

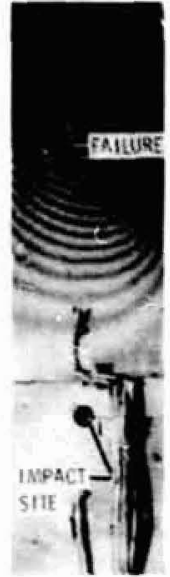

(b) Failed specimen.

Fig. 25. Out-of-plane deflection patterns for an unstiffened quasi-isotropic laminate with impact damage.

\section{Stiffened Panels with Postbuckling Strength}

The postbuckling strength of stiffened panels is limited by a skin-stiffener separation failure mode. Stiffened graphite-epoxy panels with 16- and 24-ply quasi-isotropic skins were tested by Starnes, Knight and Rouse (1982). The stiffener spacing for each panel tested was either $10.2,14.0$ or $17.8 \mathrm{~cm}$, and all stiffeners were identical. Panels with low-speed impact damage were also tested.

Postbuckling behavior of stiffened panels. The effect of varying skin thickness and stiffener spacing on the postbuckling behavior of the panels is shown in Fig. 26. The results indicate that each specimen has some postbuckling strength and that specimens with lower initial buckling strains can be loaded to a greater multiple of the buckling strain before failing. Typical membrane strain distributions in the skin between stiffeners on typical 16-ply-skin panels with different stiffener spacings are shown just before failure in Fig. 27. The filled circles on Fig. 27 represent the average strain from back-to-back strain gages and the curves are faired through the strain gage data. The results are similar to those for the unstiffened panel tests. The membrane strains are higher at the stiffeners and lower in the middle of a skin bay. All panels failed in a similar manner and

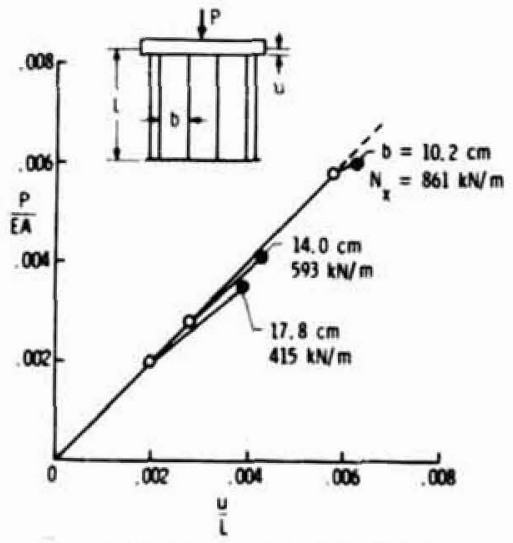

- BUCKLING

- falluRe

-..- EXTENSION OF

PREBUCKLING PATH

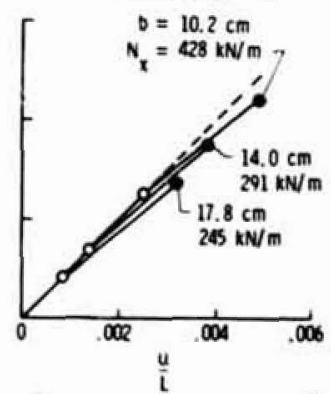

Specimens with 24-ply skins. Specimens with 16-ply skins.

Fig. 26. Postbuckling response of stiffened graphite-epoxy panels with quasi-isotropic skins. 


\section{ORICINAL PAGE IS \\ OF POOR QUALTT}
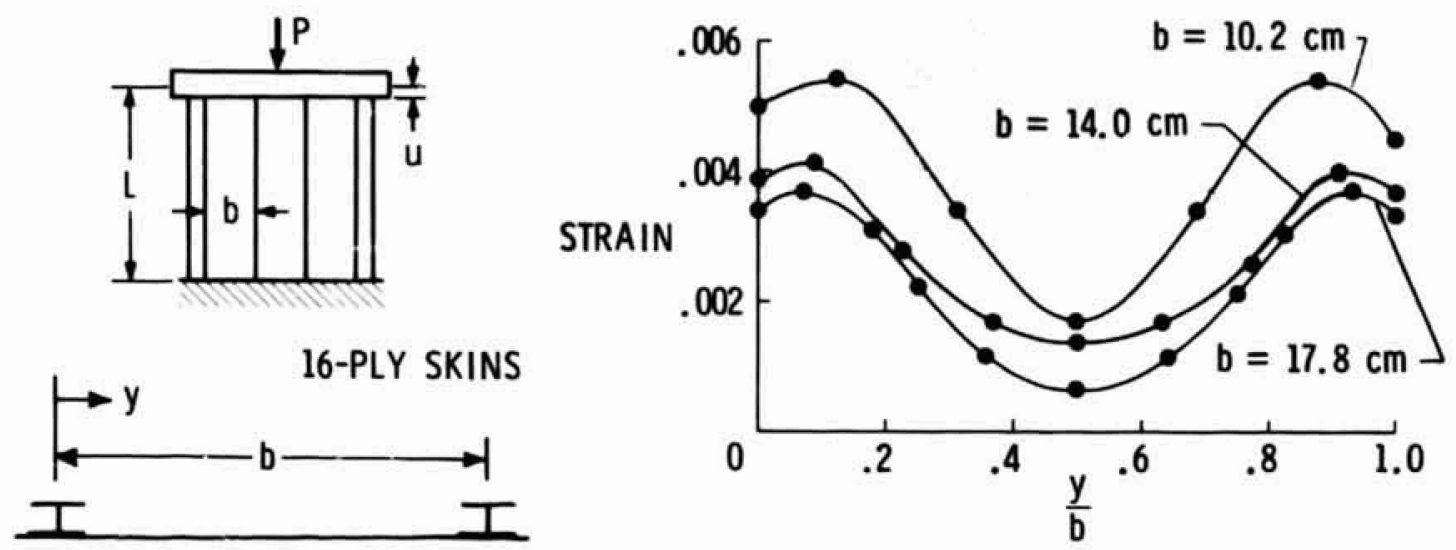

Fig. 27. Longitudinal membrane strain distribution across the skin between stiffeners of panels with 16-ply skins just before failure.

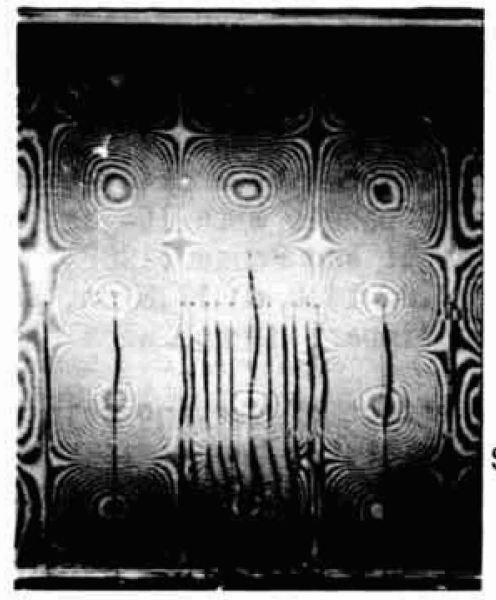

(a) Out-of-plane deflection pattern.

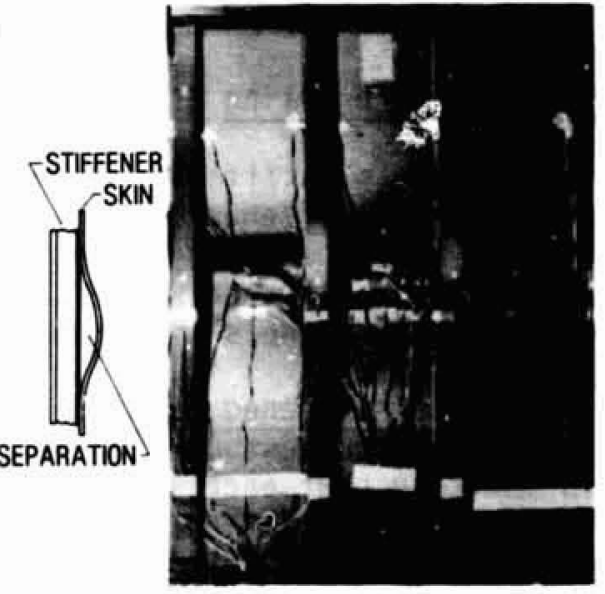

(b) Rear view of failed panel.

Fig. 28. Out-of-plane deflection pattern and failure mode of a stiffened graphite-epoxy panel.

a typical failed specimen is shown in Fig. 28. Failure occurred when the skin and the stiffeners separated from one another in the interior of the panel as shown in Fig. 28b. Apparently, the large out-of-plane deflection gradients, represented by the moire-fringe pattern for the skin of a typical panel just before failure shown in Fig. 28a, couple with the large skin strains near the stiffeners (e.g., Fig. 27) to cause interlaminar failures to occur in the stiffener region.

A comparison between test results and analytical results obtained with the STAGS analysis code is shown in Fig. 29 for a typical panel with a 16-ply quasi-isotropic skin and $17.8-\mathrm{cm}$ stiffener spacing. Typical results for end shortening u normalized by the calculated end shortening at buckling u $\mathrm{cr}$ (Fig. 29a), out-of-plane deflection $w$ near a point of maximum out-of-plane deflection normalized by the skin thickness $t$ (Fig. 29b), and surface strains e near a point of maximum out-of-plane deflection normalized by the calculated strain at buckling $e_{c r}$ (Fig. 29c) are shown as a function of the applied load $p$ normalized by the calculated buckling load $P_{\mathrm{Cr}}$. The open circles represent test data and the curves represent analytical predictions. The results correlate well up to failure. A moire-fringe pattern corresponding to the out-of-plane deflections of the specimen just before failure is shcwn in Fig. 30a. A contour plot of the out-of-plane skin deflections determined by STAGS for the corresponding load is shown in Fig. 30b. 


\section{CINALILAL WAGE IS \\ OF POOR QUALITY}

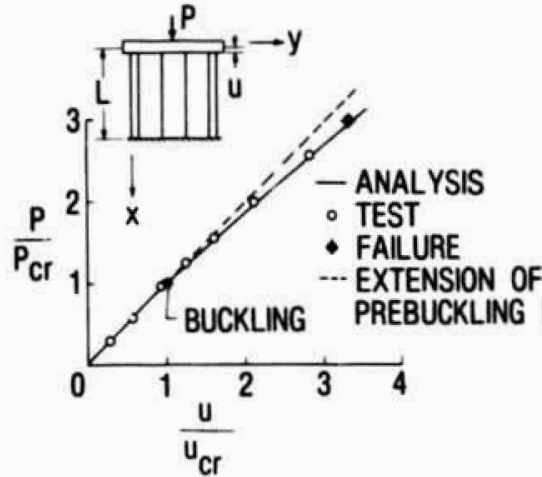

(a) End shortening.

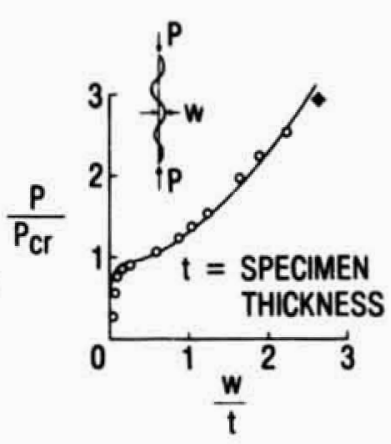

(b) Out-of-plane deflection.

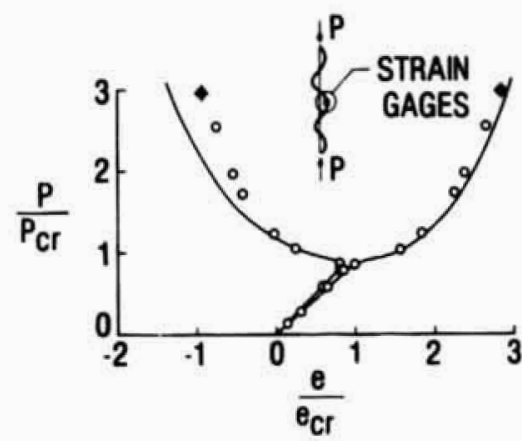

(c) Longitudinal surface strains.

Fig. 29. Comparison of experimental and analytical postbuckling results. $t=$ skin thickness.

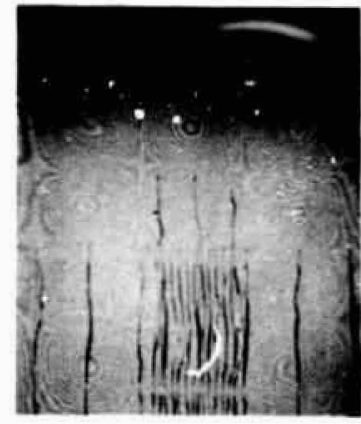

(a) Experiment.
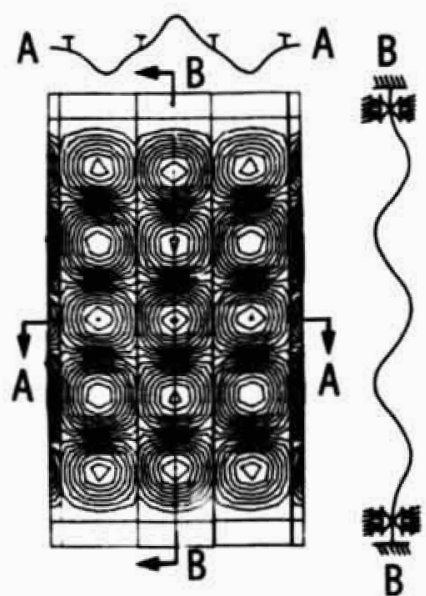

(b) Analysis.

Fig. 30. Comparison of experimental and analytical out-of-plane deflection patterns for a stiffened panel.

Also shown in Fig. 30b are the shapes of the longitudinal and lateral components of this postbuckling solution at panel midwidth and midlength, respectively. These results indicate that the analysis accurately predicts the out-of-plane skin deflections for the entire panel.

Effects of impact damage on postbuckling strength. The effects of low-speed impact damage on the postbuckling behavior of stiffened graphite-epoxy panels were studied by Starnes, Knight and Rouse (1982) by subjecting several panels to impact damage and then loading the panels to failure. Panels with 16- and 24-ply quasiisotropic skins and four equally spaced stiffeners $10.2 \mathrm{~cm}$ or $17.8 \mathrm{~cm}$ apart were impacted at speeds ranging from 66 to $103 \mathrm{~m} / \mathrm{s}$. All panels were impacted in the skin at a stiffener attachment flange and some panels were also impacted in the skin midway between two stiffeners. There was some visually detectable darnage in all cases. The effects of impact damage on the postbuckling behavior of the panels are shown in Fig. 31. Initial buckling is indicated by the open circles on the figures, aild specimen failure is indicated by the filled circles. Data for panels with no impact damage $(V=0)$ are shown for comparison. These results indicate 


\section{ORIGINAL PAGE IS
OF POOR QUALITY}
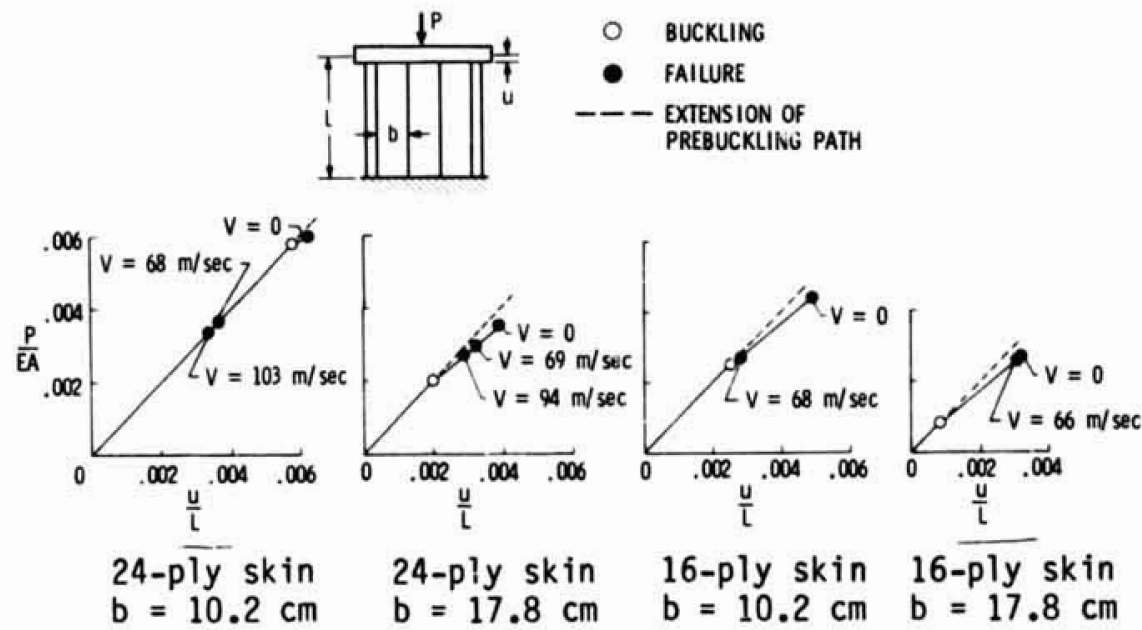

Fig. 31. Effect of low-speed impact damage on the postbuckling response of stiffent panels with quasi-isotropic skins. $b=$ stiffener spacing.

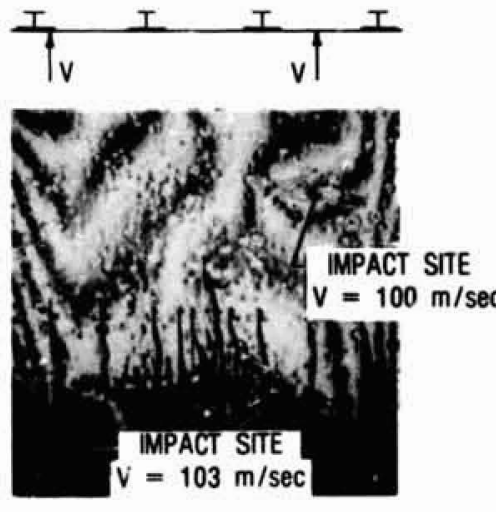

(a) Moire-fringe pattern just before failure.

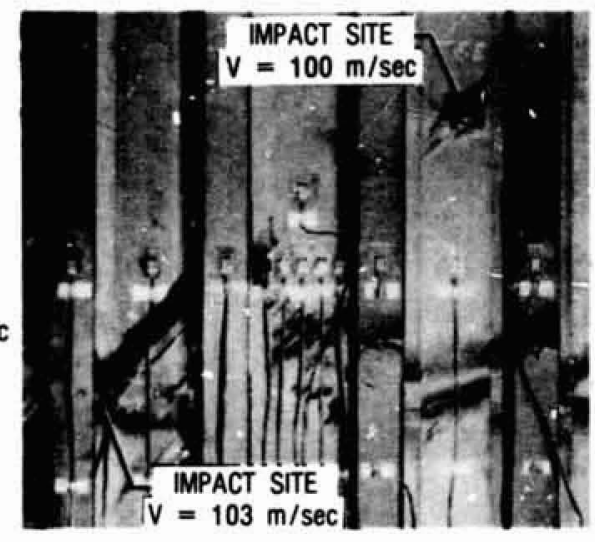

(b) Rear view of failed panel

Fig. 32. Impact damaged panel with a 24-ply skin and a 10.2-cm stiffener spacing.

that impact damage can degrade the postbuckling strength of stiffened panels. The damaged panel with 24-ply skins and 10.2-cm stiffener spacing failed before buckling; all other damaged panels failed after buckling. All damaged panels failed as a result of the impact damage inflicted in the skin at a stiffener attachment flange. The front view of a panel with a $24-p l y$ skin and $10.2-\mathrm{cm}$ stiffener spacing with two damage sites is shown just before failure in Fig. 32a. The local impact damaged regions are indicated in the moire-fringe patterns. The damage in the skin midway between stiffeners (upper right impact site in Fig. 32a) has propagated across the skin bay to the adjacent stiffeners and arrested. The damage in the skin at the stiffener attachment flange (lower left impact site) is contained in the stiffener region. A rear view of this panel after failure is shown in Fig. 32b and indicates that the damage at the stiffener attachment flange initiated failure of the panel rather than the more visually detectable damage midway between the stiffeners. It appears that damage near a stiffener attachment flange can reduce postbuckling strength more than damage in the skin midway between itiffeners. The results shown in Fig. 31 indicate that panels with higher buckling strains appear to be affected more by impact damage than panels with lower buckling strains. 


\section{CONCI.UDING REMARKS}

A summary of results from several NASA studies on failure characteristics of laminated graphite-epoxy structural components loaded in compression is presented and mechanisms that initiate failure are discussed. Results from studies of both buckling-resistant laminates and structural components with postbuckling strength indicate that the compressive strength of graphite-epoxy components can be reduced significantly by the effects of low-speed impact damage and by strain concentrations near circular holes. Results also indicate that the postbuckling strength of a graphite-epoxy component can be limited by failures in the highly strained and deformed regions.

Low-speed impact damage can cause local delaminations and other local damage to occur in graphite-epoxy laminates. A local delamination divides a laminate into several sublaminates in the damaged area. These sublaminates have lower bending stiffnesses than the original laminate and can buckle locally at applied strains well below the failure strains of the undamaged laminate. When the stresses at the boundary of the buckled delamination exceed the ultimate stress of the resin, the dt lamination can propagate to fail the laminate. A compressively-loaded laminate can be made delamination resistant by stitching the laminate through the thickness with high tensile strength threads or by using a delamination-resistant resin material. A delamination-resistant laminate subjected to impact damage fails by local transverse shear crippling at a strain level above that of a delamination-prone laminate subjected to similar impact conditions.

The strain concentrations near a circular hole in a graphite-epoxy laminate can cause the highly-strained fibers near the hole to buckle locally. These buckled fibers can fail, and the resulting local damage can propagate by a combination of shear crippling and delamination to fail the laminate. A failure analysis based on a point stress failure criterion can be used to predict the failure of compressively-loaded laminates with holes. The analysis accounts for the effects of hole size and laminate width on failure and heuristically accounts for any strainconcentration relief that may occur near the hole. Comparing results from failure analysis for circular holes with impact damaged results indicates that holes can have more effort or less effect on compressive-strength degradation than impact damage depending on hole size and extent of impact damage.

Experimental results indicate that laminated graphite-epoxy structural components can be designed to support compressive loads beyond initial buckling. The postbuckling response of these components can be predicted accurately with a nonlinear analysis. Failure of unstiffened laminates with postbuckling strength can occur along a buckling-mode nodal line in a transverse shear failure mode. Apparently, the increased membrane strains near the laminate edges couple with the out-of-plane deflection gradient at the nodal lines to induce sufficient transverse shearing loads to fail the laminate. Failure of stiffened panels with postbuckling strength can initiate in a skin-stiffener interface region. Apparently, the high strains that exist near the stiffeners following skin buckling are sufficient to cause a local separation of the stiffeners from the skins that contributes to the overall panel failure.

Low-speed impact. damage and circular holes can reduce the postbuckling strength of graphite-epoxy structural components loaded in compression. Components with relatively high initial buckling strains are affected more severely by low-speed impact damage and circular holes than those components with lower initial buckling strains. The location of the impact-damage site can also affect postbuck? ing strength. Impact damage near a stiffener or a restrained iaminate edge where relatively high postbuckling membrane strains exist can degrade postbuckling com- 
pressive strength more than impact damage in the skin between stiffeners where the membrane strains are relativolv low.

\section{REFERENCES}

Almroth, B. 0., and F. A. Brogan (1978). The STAGS computer code. NASA CR-2950. Chai, H. (1982). The growth of impact damage in compressively loaded laminates. Ph.D. Dissertation, California Institute of Technology, Pasadena, California. Chai, H., C. D. Babcock, ard W. G. Knauss (1981). One dimensional modelling of failure in laminate plates by delamination buckling. Int. J. of Solids and Structures, 11, 1069-1083.

Dykes, B. C. (1970). Analysis of displacements in large plates by the gridshadow moire technique. Proc. Fourth int. Conf. on Experimental Stress Analysis, Cambridge, England.

Howland, R. C. J. (1930). On the stresses in the neighbourhood of a circular hole in a strip under tension. Proc. R. Soc. (Londori), A229, 49-86.

Mikulas, M. M. (1980). Failure prediction techniques for compression loaded composite laminates with holes. NASA CP? 142.

Rhodes, M. D., M. M. Mikulas, and P. E. McGowan (1982). Effect of orthotropic properties and panel width on the compression strength of graphite-epoxy laminates with holes. Proc. AIAA/ASME/ASCE/AHS 23rd Structures, 'tructural Dynamics and Materiais Conf., New Orleans, Louisiana

Rhodes, M. D., and J. G. Williams (1981). Concepts for improving the damage tolerance of composite compression panels. Proc. 5th DOD/NASA Conf. on Fibrous Composites in Structural Design, New Orleans, Louisiana.

Rhodes, M. D., J. G. Williams, and J. H. Starnes (1977). Effect of low-velocity imnact damage on the compressive strength of graphite-epoxy hat-stiffened panels. NASA TN D-8411.

Rhodes, M. D., J. G. Williams, and J. H. Starnes (1978). Effect of impact damage on the compression strength of filamentary-composite hat-stiffened panels. SAMPE Engineering Series, 23, 300-319.

Rhodes, M. D., J. G. Williams, and J. H. Starnes (1979). Low velocity impact damage in graphite-fiber reinforced epoxy laminates. Proc. of 34th Annual Conf. Reinforced Plastics/Composite Institute, The Society of the Plastics Industry, New Orleans, Louisiana.

Starnes, J. H., N. F. Knight, and M. Rouse (1982). Postbuckling behavior of selected flat stiffened graphite-epoxy panels loaded in compression. Proc. AIAA/ASME/ASCE/AHS 23rd Structures, Structural Dynamics and Materials Conf., New Orleans, Louisiana.

Starnes, J. H., M. D. Rhodes, and J. G. Williams (1979). Effect of impact damage and holes on the compressive strength of a graphite/epoxy laminati. Nondestructive Evaluation and Flaw Criticality for Composite Materials, ASTM STP 696, 145-171.

Starnes, J. H., and M. Rouse (1981). Postbuckling and failure characteristics of selected flat rectangular graphite-epoxy plates loaded in compression. Proc. AIAA/ASME/ASCE/AHS 22nd Structures, Structural Dynamics and Materials Conf., Atlanta, Georgia.

Williams, J. G., and M. M. Mikulas (1975). Analytical and experimental study of structurally-efficient composite hat-stiffened panels loaded in compression. Proc. AIAA/ASME/SAE 16th Structures, Structural Dynamics and Materials Conf., Denver, Colorado.

Williams, J. G., and M. D. Rhodes (1981). The effect of resin on the impact damage tolerance of graphite-epoxy laminates. NASA TM 83213.

Whitney, J. M., and R. J. Nuismer (1974). Stress fracture criteria for laminated composites containing stress concentrations. $\mathfrak{j}$. of Composite Material,, 8 , 253-265. 